\title{
Understanding the Occurrence of Two Total Floats in One Activity and Schedule Crashing Approaches for That Situation
}

\author{
Boong Yeol Ryoo", Mike T. Duff \\ Department of Construction Science, Texas A\&M University, College Station, USA. \\ *Corresponding author: Email: bryoo@tamu.edu \\ Received May $15^{\text {th }}, 2013$; revised July $17^{\text {th }}, 2013$; accepted July $27^{\text {th }}, 2013$ \\ Copyright (C) 2013 Boong Yeol Ryoo, Mike T. Duff. This is an open access article distributed under the Creative Commons Attribu- \\ tion License, which permits unrestricted use, distribution, and reproduction in any medium, provided the original work is properly \\ cited.
}

\begin{abstract}
Critical Path Method (CPM) Scheduling has proven to be an effective project management tool. However, teaching the topic has proven it difficult to include all elements of CPM yet keep it simple enough for students to understand. In an effort to simplify the teaching of critical path method scheduling, the issue of two total floats in an activity does not get the attention necessary to address its occurrence. The objective of this paper is to present a mathematical method to show multiple total floats are possible for an activity. Also presented are suggestions for schedule crashing when multiple total floats are found. Two totals floats can be found if constraints (Lag or Lead) or non-Finish-to-Start (FS) relationships, or both are used in a network diagram. Situations are possible where an activity may have a start total float (STF) of zero but have a finish total float (FTF) greater than zero, or vice versa. Because the critical path generally follows the zero total float, these situations, where either the STF or the FTF is critical while the other is not, determine how the critical path activity must be controlled and crashed. This paper will present approaches of how to crash the schedule when a portion of the activity, either start or finish, is critical. Also presented will be methods to teach the subject matter with or without the use of scheduling software. Critical Path Method was revisited to see what the minimal conditions are needed to have activities with two total float. Generalized crashing methods were studied to see if the methods can be used when two total floats exist.
\end{abstract}

Keywords: Critical Path Method; Multiple Total Floats; Schedule Crashing; Constraints; Lag/Lead

\section{Introduction}

\subsection{Background}

The construction schedule is a communication tool at the construction site [1]. Due to the fact that specialty contractors execute contractually responsible tasks for a project and they may not be able to work together directly, a well-developed construction schedule can be used to monitor construction operations, project resources, potential risks, and desired quality of the project. The schedules are made up of a list of deliverables to be completed, construction activities required for the deliverables, and administrative activities to support the construction activities [1]. The administration activities are the project managers' or superintendents' activities to the schedule to oversee the management responsibilities for general contractor's or specialty contractors' construction operations.

The network diagramming method is commonly used in building construction. Typically four activity relationships are used to represent a sequence or constraint between two activities: Finish-to-Start, Finish-to-Finish, Start-to-Start, and Start-to-Finish [2]. The critical path method is widely used for project planning in the commercial construction industry to find the longest path of activities to complete a project. First, four different dates such as early start date, early finish date, late start date, and late finish date for each activity are calculated using the Forward Pass and Backward Pass methods. Then, at least two floats, total float (TF) and free float (FF) for each activity, are calculated in order to identify if the activity can be delayed without delaying the whole project or immediate following activities. Finding zero TF activities is the first key to identify critical activities be- 
cause FF of the critical activities is also zero. Commonly TF for an activity is calculated by determining the difference between the early dates or late dates of the activity assuming that the start TF and finish TF of an activity are the same. This calculation has been used even though multiple relationships are used between two activities. However, if multiple relationships or lead/lag time is used, the start TF and finish TF of an activity may not be the same. Related to construction scheduling, Feigenbaum [3] and Mubarak [4] briefly stated a possibility of multiple TF for an activity while others did not explain the possibility [3-17]. Thus, the start and finish dates can be calculated but the floats cannot be calculated accurately under the above conditions.

In scheduling real world construction projects multiple relationships are often used between activities. Lag or lead times are often used to show necessary time gaps in these relationships. In addition, constraints are also frequently added to impose limitations on activities. These could add another level of complexity to the schedule because the start TF and the finish TF of an activity can be different. When this happens, only the beginning or ending point of the activity becomes critical. This paper is to investigate conditions which cause two total floats for an activity and the affect this has on crashing the schedule.

\subsection{Observation}

When multiple relationships or a lag/lead time is used in a CPM diagram a situation can arise where there are two different total floats for an activity, start total float (STF) and finish total float (FTF). STF is the amount of delay at the beginning of the activity whereas FTF is the amount of delay at the end of the activity without delaying the whole project. When this happens, either the start or finish dates of the activity, whichever is critical, must be followed because the critical path follows zero total floats. It affects how a project can be managed based on where the critical path follows.

In order to find the maximum time reduction with the minimum cost increase, the activity with the cheapest crashing cost on the critical path of the project is always selected [1]. When STF and FTF are different, shortening activity durations may not be enough to reduce its duration because relationships/constraints dictate the start or finish date of the activity. Thus the current critical path crashing methods must be reexamined to determine if this is taken into consideration and acted upon.

\section{Determining Critical Paths}

\subsection{Current Critical Path Calculation Methods}

The critical path method is widely used to find the critical paths and critical activities in network schedules.
Through the performing of the forward pass calculation the early start date (ESD) and early finish date (EFD) for an activity is calculated. The late start dates (LSD) and late finish date (LFD) of each of the activities is calculated by performing the backward pass calculation. Once the ESD, EFD, LSD, and LFD have been calculated then total float and free float can be determined as in Equation (1). The calculation of total float for the activity is crucial because the critical path follows the activities of zero total float [6].

$$
\mathrm{TF}=\mathrm{LSD}-\mathrm{ESD} \text { or LFD }-\mathrm{EFD}
$$

Based on the assumption that there is only one total float for the activity, scheduling programs adopt Equation (1) and only one total float for each activity is calculated. This leads to another assumption that the total float at the beginning and end of the activity is the same. It is a safe solution but not enough to effectively reduce the duration of the project because real amount of slacks are not known.

With these assumptions there is the risk of missing the two total floats for the activity. Along these same lines Mubarak [4] and Marchman and Sulbaran [13] introduced an additional equation to calculate total float for an activity as used in Equation (2). This equation, in addition to Equation (1), still only calculates one total float for the activity, but does begin to compare the difference between the start and finish of an activity.

$$
\mathrm{TF}=\mathrm{LFD}-\text { Duration }-\mathrm{ESD}
$$

Feigenbaum [3] puts forth two equations where two total floats are calculated; start total float and finish total float for an activity as shown in Equation (3) and Equation (4).

$$
\begin{aligned}
& \mathrm{STF}=\mathrm{LSD}-\mathrm{ESD} \\
& \mathrm{FTF}=\mathrm{LFD}-\mathrm{EFD}
\end{aligned}
$$

Comparing these two equations serves as a way to determine if there is an instance of two different total floats for an activity.

In the event that Equation (3) and Equation (4) are equal then this means that STF and FTF are equal. Without a lad/lead time, durations are the only factor affecting the project duration.

Free float is determined by Equation (5) and it shows how much the activity can be delayed without delaying the following activities. This cannot be used if a relationship other than finish-to-start is used. In this case, the early start date for the activity may be irrelevant because these relationships represent direct relationships between two activities not effect the early start.

$$
\mathrm{FF}=\operatorname{minimum}\left(\mathrm{ESD}_{\text {successors }}\right)-\mathrm{EFD}
$$

\subsection{Existence of Two Total Floats}

Between any two activities, there can be multiple paths 
from the first activity to the last activity. The duration of any path between two activities is the sum of the durations and lag/lead times of the activities in the path. Under normal circumstances the largest early finish date is the early start date for the immediate successor activity. However, multiple relationships, such as the addition of lag and lead times, between two activities may cause this to not be the case. The Early Start for the activity I can be calculated using Equation (6).

$$
\text { Duration of } \text { Path }_{i}=\sum_{j=0}^{k} \text { Duration }_{j}+\text { Lag }_{j}
$$

where, $i=$ any path between any two activities;

$j=$ Activity number;

$k=$ the total number of activities of each path.

As stated before, with no lags the early start date of an activity is the largest early finish date of the paths before the activity. However, when lags are used, ESD, EFD, LSD, and LFD can be calculated as shown using the following equations and demonstrated in Figure 1.

$$
\begin{gathered}
\mathrm{ESD}=\mathrm{EFD}_{\mathrm{i}}+\mathrm{Lag}_{1} \\
\mathrm{EFD}_{\mathrm{j}}=\mathrm{EFD}_{\mathrm{i}}+\mathrm{Lag}_{1}+\text { Duration }_{\mathrm{j}} \\
\mathrm{EFD}_{\mathrm{j}}=\mathrm{EFD}_{\mathrm{i}}+\mathrm{Lag}_{2} \\
\mathrm{LSD}_{\mathrm{j}}=\mathrm{LSD}_{\mathrm{k}}-\mathrm{Lag}_{4} \\
\mathrm{LFD}_{\mathrm{j}}=\mathrm{LSD}_{\mathrm{k}}-\mathrm{Lag}_{2} \\
\mathrm{LFD}_{\mathrm{j}}=\mathrm{LSD}_{\mathrm{k}}-\mathrm{Lag}_{4}+\text { Duration }_{\mathrm{j}}
\end{gathered}
$$

Equations (13) and (14) show the distance of two connected activities. In order to maintain the same distance between two activities, Equations (13) and (14) must be true. If Equations (3) and (4) yields two different total floats, the start and late dates can be calculated so that the calculation of STF and FTF become possible.

$$
\begin{aligned}
& \operatorname{Lag}_{1}+\text { Duration }_{j}=\operatorname{Lag}_{2} \\
& \operatorname{Lag}_{4}-\text { Duration }_{\mathrm{j}}=\mathrm{Lag}_{3}
\end{aligned}
$$

In order to maintain the same duration for Activity $j$, the duration can be calculated from two linked lags as in Equation (15).

$$
\text { Duration }_{\mathrm{j}}=\mathrm{Lag}_{2}-\mathrm{Lag}_{1}=\mathrm{Lag}_{4}-\mathrm{Lag}_{3}
$$

In Figure 1, STF and FTF are different if $\operatorname{Lag}_{2}-$ $\mathrm{Lag}_{1} \neq \mathrm{Lag}_{4}-\mathrm{Lag}_{3}$. On the other hand if the following equations, Equations (16) and (17), are true, then the possibility of different STF and FTF for the activity exists.

$$
\begin{aligned}
& \text { Duration }_{\mathrm{j}} \neq \mathrm{Lag}_{2}-\mathrm{Lag}_{1} \\
& \text { Duration }_{\mathrm{j}} \neq \mathrm{Lag}_{4}-\mathrm{Lag}_{3}
\end{aligned}
$$

Thus,

$$
\mathrm{LSD}-\mathrm{ESD} \neq \mathrm{LFD}-\mathrm{EFD}
$$

This leads to the conclusion that slacks at the beginning and end of the activity can be different as in Equation (18). Thus, as a lag/lead time is used between two activities, there is a possibility that either the start or finish date can only be critical. It is also true if multiple relationships are used to link two activities as in Figure 1.

\section{Crashing the Schedule with Two Total Floats}

\subsection{Working with a Two Total Float Example}

Figure 2 is a CPM diagram with multiple relationships and lags. While it is a nine activity example it serves to demonstrate what can occur when there are multiple relationship types and lags.

In Figure 2 the following are the critical activities:

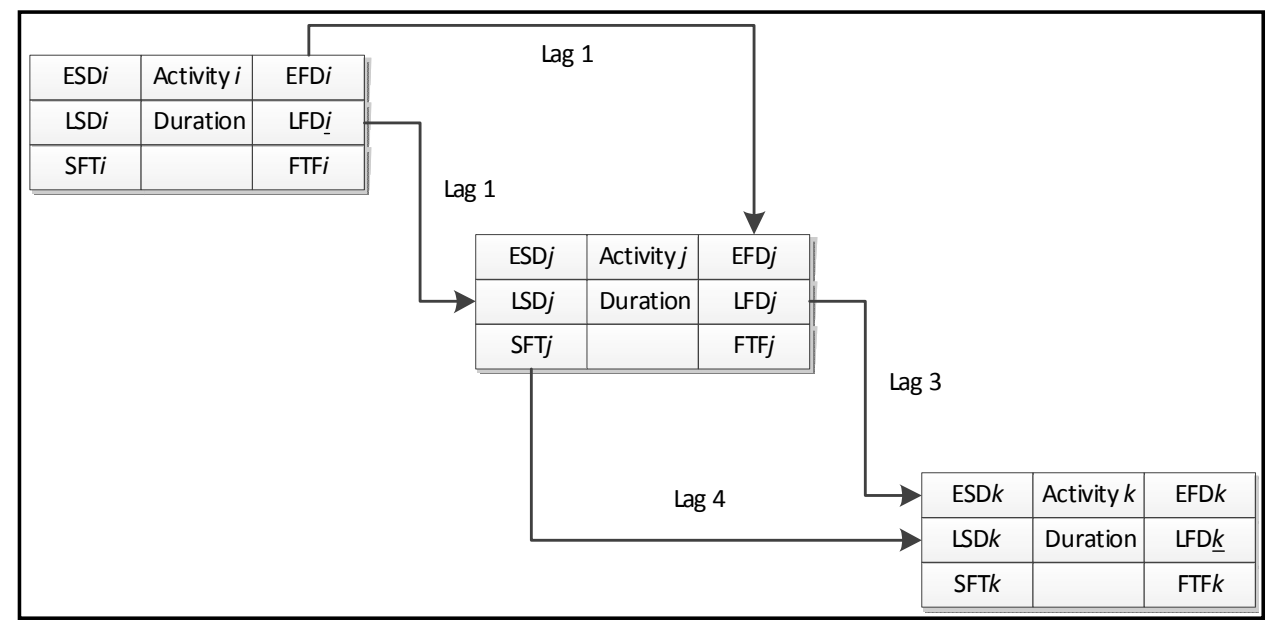

Figure 1. Diagram of lags and relationships. 


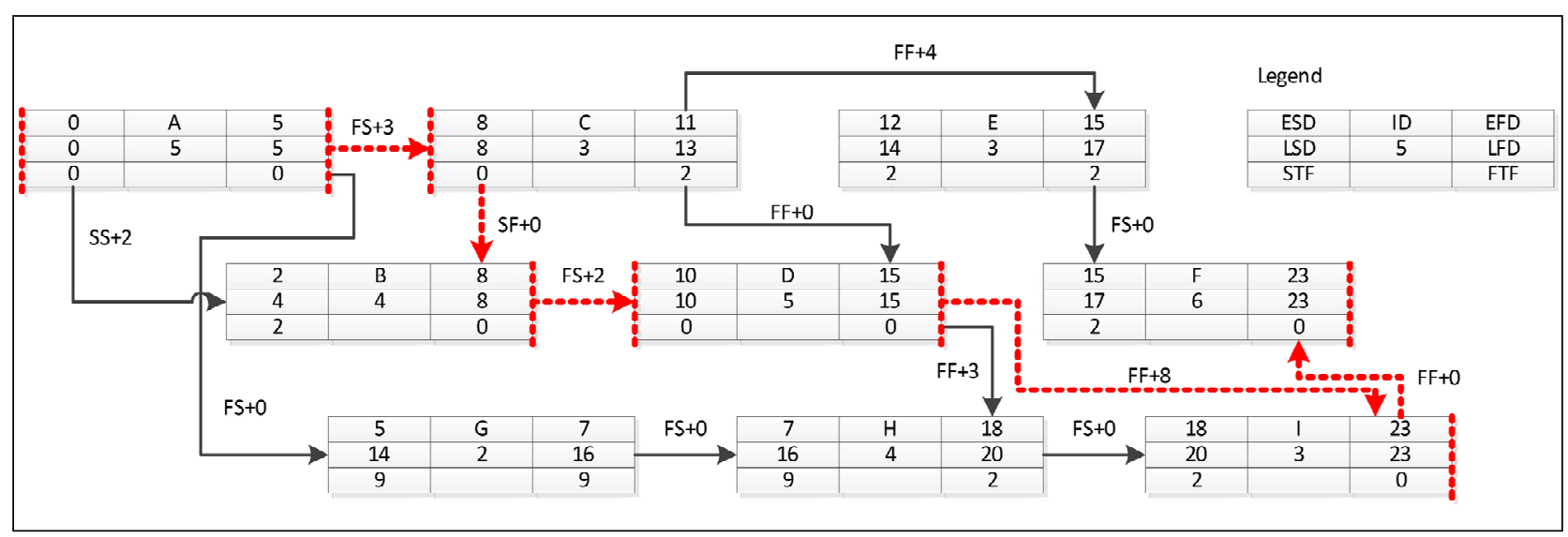

Figure 2. Two total float example with multiple relationships and lags.

- Activity A (enitre).

- The Start of Activity C.

- The Finish of Activity B.

- Activity D (entire).

- The Finish of Activity I.

- The Finish of Activity F. The project duration is 23 days and is as follows:

- All of Activity A is critical; meaning both the start date and finish date must be kept to avoid a delay in the entire project.

- The finish date of Activity B must complete on time, but the start has 2 days of float. Thus, available maximum total float of Activity B is 2 .

- The start of Activity C has zero total float and the finish has 2 day of float.

- Both the start and finish dates for Activity D are critical with zero days of float for both.

- Activity E while it is not critical has a different STF of 2 days and a FTF of 2 days. Thus, available maximum total float of Activity $\mathrm{E}$ is 2.

- While Activity F must finish on day 23 it has 2 days of start float. Thus, available maximum total float of Activity F is 2.

- Activity $\mathrm{G}$ is a non-critical activity and it has identical values for both STF and FTF. It also is the only activity that has a finish-to-start relationship with both its predecessor and successor.

- Activity H's STF is 9 days and its FTF is 2. Thus, available maximum total float of Activity B is 7 .

- The finish of Activity I has zero days of float while the start date has 2 days of float. Thus, available maximum total float of Activity $\mathrm{I}$ is 2 .

- Activities B, C, I and F are governed by their non-FS relationships.

With a hand drawn schedule, similar to the Activity on Node in Figure 2, it is possible to find these incidences of a different STF and FTF. The red hidden lines represent critical paths of the schedule. Vertical red hidden lines indicate critical dates, either start or finish dates. A few activities are reviewed as follow:

STF of Activity B is 2 and its FTF is 0 . If the activity starts on the early date, the activity can have as much as 2 days of total float at the beginning because the activity must be completed by Day 8 .

STF of Activity E is 2 and its FTF is 2. Activity E may not have 2 days of total float unless it begins on the early start date. If it is delayed more than 2 days, which is the amount of its FTF, then early dates are no longer feasible.

In the same manner, the TF of Activity $\mathrm{H}$ is only 7 even through STF of Activity $\mathrm{H}$ is 9 because there is a two day lag at the end of Activity H. It is required to begin Activity $\mathrm{H}$ on its early start date to maximize its slack of 9. Otherwise the TF of Activity $\mathrm{H}$ will be reduced to 2 . Utilization of 9 day delay on Activity $\mathrm{H}$ at the beginning forces to use the late schedule for the rest of the project.

\subsection{Comparison of Scheduling Software}

Two scheduling softwares, Microsoft Project (MSP) and Primavera P6 Project Manager (P6), were used to compare the results of the same schedule. As shown in Tables 1 and 2, Microsoft Project ${ }^{\circledR}$ and Primavera $6^{\circledR}$ show different results than the hand calculation in Figure 2.

The main issue is the algorithm written by the programmers to deal with the critical path calculations of the logic. For instance in MSP while there is a way to show both STF and FTF, MSP does not show the differences in activities B, C, E, F, H, and I found in the hand calculated diagram. With the scheduling programs, early start and early finish dates are less flexible than hand calculation if there is a lag or non-Finish-Start relationship such as Activities B, E, H, and F. The programming of these portions of the software has not been set up to accept all the implications of these different relationships and lags. This eliminates some potential analysis from the beginning, because MSP only allows one relationship between 
Table 1. Schedule data and activity dates from Microsoft project sort by early start date.

\begin{tabular}{|c|c|c|c|c|c|c|c|c|c|}
\hline ID & Task Name & Duration (days) & Predecessors & $\begin{array}{c}\text { Early Start } \\
\text { Date }\end{array}$ & $\begin{array}{c}\text { Early Finish } \\
\text { Date }\end{array}$ & $\begin{array}{c}\text { Late Start } \\
\text { Date }\end{array}$ & $\begin{array}{l}\text { Late Finish } \\
\text { Date }\end{array}$ & Total Float & Free Float \\
\hline 1 & Total & 23 & - & 1 & 23 & 1 & 23 & 0 & 0 \\
\hline 2 & A & 5 & - & 1 & 5 & 1 & 5 & 0 & 0 \\
\hline 3 & B & 4 & $2 \mathrm{SS}+2.4 \mathrm{SF}$ & 5 & 9 & 5 & 9 & 0 & 0 \\
\hline 8 & G & 2 & 2 & 6 & 7 & 15 & 16 & 9 & 7 \\
\hline 4 & $\mathrm{C}$ & 3 & $2 \mathrm{FS}+3$ & 9 & 11 & 9 & 11 & 0 & 0 \\
\hline 5 & $\mathrm{D}$ & 5 & $3 \mathrm{FS}+2.4 \mathrm{FF}$ & 11 & 15 & 11 & 15 & 0 & 0 \\
\hline 6 & $\mathrm{E}$ & 3 & $4 \mathrm{FF}+4$ & 13 & 15 & 15 & 17 & 2 & 2 \\
\hline 9 & $\mathrm{H}$ & 4 & $8.5 \mathrm{FF}+3$ & 15 & 18 & 17 & 20 & 2 & 2 \\
\hline 7 & $\mathrm{~F}$ & 6 & $6.10 \mathrm{FF}$ & 18 & 23 & 18 & 23 & 0 & 0 \\
\hline 10 & I & 3 & $5 \mathrm{FF}+8.9$ & 21 & 23 & 21 & 23 & 0 & 0 \\
\hline
\end{tabular}

Table 2. Schedule data and activity dates from primavera 6 sorts by early start date.

\begin{tabular}{|c|c|c|c|c|c|c|c|c|}
\hline Task Name & Duration (days) & Predecessors & $\begin{array}{c}\text { Early Start } \\
\text { Date }\end{array}$ & $\begin{array}{c}\text { Early Finish } \\
\text { Date }\end{array}$ & $\begin{array}{c}\text { Late Start } \\
\text { Date }\end{array}$ & $\begin{array}{c}\text { Late Finish } \\
\text { Date }\end{array}$ & Total Float & Free Float \\
\hline Total & 23 & - & 1 & 23 & 1 & 23 & 0 & 0 \\
\hline A & 5 & - & 1 & 5 & 1 & 5 & 0 & 0 \\
\hline B & 4 & $\mathrm{~A}, \mathrm{C}$ & 5 & 9 & 5 & 9 & 0 & 0 \\
\hline G & 2 & A & 6 & 7 & 15 & 16 & 9 & 9 \\
\hline $\mathrm{C}$ & 3 & A & 9 & 11 & 8 & 11 & 0 & 0 \\
\hline $\mathrm{D}$ & 5 & $\mathrm{~B}, \mathrm{C}$ & 11 & 15 & 11 & 15 & 0 & 0 \\
\hline E & 3 & $\mathrm{C}$ & 13 & 15 & 15 & 17 & 2 & 2 \\
\hline $\mathrm{H}$ & 4 & $\mathrm{D}, \mathrm{G}$ & 15 & 18 & 17 & 20 & 2 & 2 \\
\hline $\mathrm{F}$ & 6 & $\mathrm{E}, \mathrm{I}$ & 18 & 23 & 18 & 23 & 0 & 0 \\
\hline I & 3 & H, D & 21 & 23 & 21 & 23 & 0 & 0 \\
\hline
\end{tabular}

two activities.

Because of this hand calculation methods and scheduling programs must be taught together so students can experience the difference of the results from hand calculation and schedule programs. Also in the industry it is a way to double check the logic of a schedule. Figure 2 shows that the focus on the activities affected by non FS or activities with Lags is all that is necessary to determine if there are differences in STF and FTF. In other words, it is not necessary to hand draw the logic of the entire schedule, just those activities affected by lags and non-finish-to-start relationships.

As shown in Tables 1 and 2, totals for Activities E, G, and $\mathrm{H}$ from both programs are the same. Activity $\mathrm{B}$ has a 2day SFT but it was not included in the calculation because the finish date of Activity B is critical. Reversely Activity C's FTF is 2. Activity C is forced to obey the early start date because it was critical. However Activity F's finish date is critical so it is forced to follow the late dates.

Activity $\mathrm{G}$ demonstrates the differences in algorithms between MSP and P6. The relationship between $\mathrm{G}$ and $\mathrm{H}$ is a finish-to-start with no lag or lead. The total float for $\mathrm{G}$ was calculated correctly, however, for free float it shows their way of trying to deal with the difference between the STF and FTF of Activity H. The free float given to Activity $\mathrm{G}$ does not belong to it. However, because both P6 and MSP do not know what to do with the situation in Activity $\mathrm{H}$ they default to what they can do. MSP does take into consideration the FTF of two days for Activity $\mathrm{H}$, by taking it away from the Free Float listed for Activity G.

\subsection{Crashing the Schedule}

To achieve the least expensive duration reduction, or crashing, of the schedule is to find the cheapest and shortest option the duration of the project can be reduced. This is a fairly common occurrence on projects. The following steps are generally accepted to reduce the duration of the project to meet the revised end date. In order to find the minimum cost schedule, trade-off analysis is necessary to find the lowest cost alternatives in each step. Generally the lowest crashing cost activities are selected and crashed. Brunnhoeffer and Celik [2] presented a 
general algorithm for crashing the schedule.

- Identify the critical path.

- Select the cheapest crashing cost activity.

- Crash the selected activity 1) to the next longest path; 2) until the critical path changes; or 3) until crashing is infeasible. The first approach is preferred because it does not crash the schedule more than necessary.

This approach can be used if the early total float and finish total float for an activity are the same. However, in the schedule in Figure 2 if Activity $\mathrm{C}$ were to be shortened because it is listed as critical according to both P6 and MSP, it would not have an effect on the end of the total project because only the start of Activity $\mathrm{C}$ is critical. Relationships that are not FS or have Lags do not lend themselves to traditional crashing methods.

Table 3 lists the activities found in Figure 2 with their data needed for crashing. While the activities listed in Tables $\mathbf{1}$ and $\mathbf{2}$ are on the critical path only two activities are entirely critical, Activities A and D. The start date of Activity $\mathrm{C}$ is critical whereas the finish dates of Activities B, F, and I are critical. Reducing the duration of B does not affect the total project duration because the relationship from Activity $\mathrm{C}$ to Activity $\mathrm{B}$ has a greater effect than that of Activity A to Activity B. Activity F, which is on the critical path and at $\$ 300$ per day is the cheapest activity to crash, can be reduced by 2 days. The total project duration will not be reduced because of its constraint from Activity I. Thus it is recommended to see if the lag from Activity I can be revised. The relationship between Activity I and Activity F is Finish-to-Finish (FF) with zero lag. It cannot be crashed. However it will have more total float if it is crashed. The next choice is Activity $\mathrm{B}, \$ 500$ per day; it can be reduced by 1 day. However, because Activity B has a constraint enforced by Activity $\mathrm{C}$ to the finish date of Activity $\mathrm{B}$, the project duration will not be affected. Activity C's start date is critical and it is the next alternative, $\$ 700$ per day. Reducing the duration of Activity $\mathrm{C}$ may or may not be beneficial to the project. Reducing its duration can affect the finish date of Activity D which happens to be critical. Otherwise it may not affect the project duration. However, since the entire activity of Activity A and Activity D have the same priority, $\$ 1000$ per day, reducing their duration can affect the duration of the project.

Another example of the effects of non FS relationships is seen in Figure 3, which is a portion of the logic diagram for placing a footing. The inspection needs to be completed on Day 13, however, it can start as early as Day 10. In other words, according to the logic, there needs to be an inspection as the rebar and formwork is being placed, there also needs to be an inspection done when the Footing concrete is placed. This problem would best be solved by splitting the inspection activity into two separate activities to take care of both the needs spelled out by the logic. This example does serve to demonstrate some of the issues that can occur with the use of lags and non-finish-to-start relationships to take care of some logic needs of a project.

As shown in Figure 2, some activities in the critical paths are critical based on either their start date or finish date. Conventional crashing guidelines cannot be applied to reduce the project duration because it assumes the whole activity is critical $[2,12]$. Based on the guideline, reduction in activity duration on the critical path causes automatic reduction in schedule time. However, if either only the start date or finish date is critical, crashing a critical activity does not cause an automatic duration reduction in the schedule as.

When this is the case, especially when STF of an activity is critical, a revision of relationships to the activity is suggested prior to crashing the activity. The following additional suggestions should be considered:

- Identify the critical path.

- Reduce lag times affecting the critical path.

- Revise relationships from finish-to-start, start-to-finish, or finish-to-finish to start-to-start relationships.

- Select the cheapest crashing cost activities and 1) see if any relationship can be crashed if the finish date of the activity is only critical; 2) do not attempt crash it if it is not; and 3) do not crash the activity if only the start date is critical;

- Crash the least expensive activity if both start date and finish date are critical.

\section{Suggestions}

When constraints are used in a project, this creates the need to use non FS relationships and lags and leads. This leads to two observations. The first observation is if lags and leads are used there is a possibility of the STF being different than the FTF. Secondly, multiple relationships between activities can also create these differences. Also, other constraints not placed by management or the owner can also lead to the difference between STF and FTF.

When this is the case, calculations of STF and FTF are recommended. It is only necessary to do these calculations on those activities affected by the lag/lead or non FS relationship. In such cases, it is recommended these be done by hand and not be dependent on the scheduling software to tell if the start date, finish date, or entire activity is critical.

Secondly, before choosing a method to crash the schedule with an activity with two total floats it must be determined if the start date is critical or the finish date. If the start date is critical the predecessors need to be looked at to determine if the relationship or the activity is critical. In the event of two total floats the relationship should be crashed. If it is a lag relationship the lag needs 
Table 3. Schedule data for crashing.

\begin{tabular}{cccccccc}
\hline Activity & $\begin{array}{c}\text { Normal Duration } \\
\text { (days) }\end{array}$ & $\begin{array}{c}\text { Crash Duration } \\
\text { (days) }\end{array}$ & $\begin{array}{c}\text { Normal Cost } \\
(\$)\end{array}$ & $\begin{array}{c}\text { Crash } \\
\text { Duration }(\$)\end{array}$ & $\begin{array}{c}\text { Maximum } \\
\text { Reduction } \\
\text { (days) }\end{array}$ & $\begin{array}{c}\text { Cost to crash per } \\
\text { period }(\$ / \text { day) }\end{array}$ & Critical Dates \\
\hline A & 5 & 3 & 5000 & 3000 & 1 & 1000 & Start Date, Finish Date \\
B & 4 & 3 & 2000 & 1500 & 1 & 500 & Finish Date \\
C & 3 & 2 & 2100 & 1400 & 1 & 700 & Start Date \\
D & 5 & 3 & 5000 & 3000 & 2 & 1000 & Start Date, Finish Date \\
E & 3 & 3 & 1800 & 1800 & 0 & 0 & Finish Date \\
F & 6 & 4 & 1800 & 1200 & 2 & 300 & - \\
G & 2 & 2 & 4000 & 4000 & 0 & 0 & - \\
H & 4 & 3 & 1600 & 1200 & 1 & 400 & 0 \\
I & 3 & 3 & 1500 & 1500 & 0 & Finish Date \\
\hline
\end{tabular}

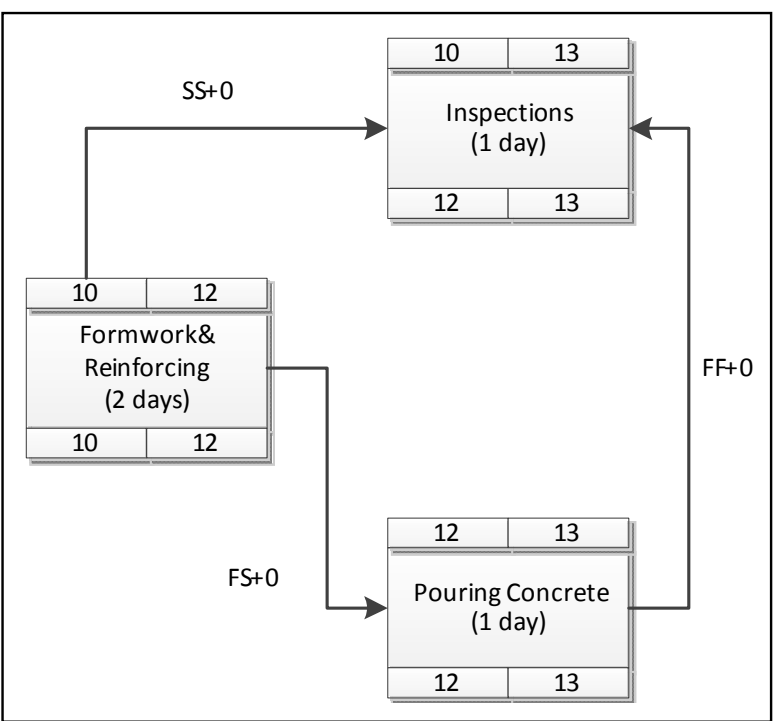

Figure 3. Concrete work logic (example used with permission).

to be crashed before the duration is crashed. It may not add any additional costs to the project unlike a duration crash.

Third, the generalized crashing method cannot be used to crash the schedule if non finish-to-start relationships and lag/lead times are used. The following is suggested: if the finish date is critical, reduce the amount of lag. The relationship and lag may control the activity itself. If the start date is critical, reducing its duration may or may not affect the project duration. The critical path should be recalculated in order to find any impact.

Lastly, understanding hand calculation methods and how scheduling programs work is important in order to create realistic schedules. People involved in this area need to understand how construction logic works, as well as understand how scheduling software uses that logic to create the schedule on the screen. The decisions that are made based on a computer generated schedule have se- rious cost and time implications to a project, care should be taken to ensure the decisions are being made with correct and relevant information.

\section{REFERENCES}

[1] AGC, "Construction Planning \& Scheduling," AGC of America, Arlington, 1997.

[2] G. C. Brunnhoeffer III and B. G. Celik, "Crashing he Schedule-An Algorithmic Approach with Caveats and Comments," 2010.

[3] J. Buttelwerth, "Computer Integrated Construction Project Scheduling," Prentice Hall, Upper Saddle River, 2005.

[4] D. G. Carmichael, "Project Planning, and Control," Taylor \& Francis, London, 2006.

[5] F. E.Gould, "Managing the Construction Process," Prentice Hall, Upper Saddle River, 2005

[6] L. Feigenbaum, "Construction Scheduling with Primavera Project Planner," 2nd Edition, Prentice Hall, Upper Saddle River, 2002.

[7] S. Mubarak, "Construction Project Scheduling and Control," John Wiley and Sons, Hoboken, 2010. doi:10.1002/9780470912171

[8] T. E. Glavinich, "Construction Planning \& Scheduling," AGC of America, Arlington, 1997.

[9] T. E. Glavinich, "Construction Planning \& Scheduling Manual," AGC of America, 2004.

[10] T. Hegazy, "Computer-Based Construction Project Management," Prentice Hall, Upper Saddle River, 2002.

[11] J. W. Hinze, "Construction Planning and Scheduling," 4th Edition, Prentice Hall, Upper Saddle River, 2011.

[12] H. Kerzner, "Project Management: A Systems Approach to Planning, Scheduling, and Controlling", 10th Edition, John Wiley \& Sons, Inc., Hoboken, 2009.

[13] D. A. Marchman and T. A. Sulbaran, "Scheduling with Suretrak," 2nd Edition, Delmar Cengage Learning, Independence, 2006.

[14] J. S Newitt, "Construction Scheduling: Principles and 
74 Understanding the Occurrence of Two Total Floats in One Activity and Schedule Crashing Approaches for That Situation

Practices," 2nd Edition, Prentice Hall, Upper Saddle River, 2011.

[15] J. J. O’Brien and F. L. Plotnick, “CPM in Construction Management," McGraw Hill, Boston, 2009.
[16] T. E. Uher, "Programming and Scheduling Techniques", University of New South Wales Press Ltd., Sydney, 2003.

[17] S. C. Weber, "Scheduling Projects Principles and Practices”, Prentice Hall, Upper Saddle River, 2005. 